\title{
Creation of Local Integrated Production-Trading Systems: Actuality, Determinants, Conformity of Conditions
}

\author{
Halyna Ivanchenko \\ Department of Management and \\ Administration \\ Vinnytsia Institute of Trade and \\ Economics of Kyiv National University \\ of Trade and Economics \\ Vinnytsia, Ukraine \\ galina.valeriivna@gmail.com \\ Olexandra Shaleva \\ Enterpreneurship, Trade and Logistics \\ Departent \\ Lviv University of Trade and \\ Economics \\ Lviv, Ukraine \\ volex2007@ukr.net
}

\author{
Nataliia Mitsenko \\ Department of Economics \\ Lviv University of Trade and \\ Economics \\ Lviv, Ukraine \\ talami1412@gmail.com
}

\author{
Ihor Mishchuk \\ Enterpreneurship, Trade and Logistics \\ Departent \\ Lviv University of Trade and \\ Economics \\ Lviv, Ukraine \\ igmislog@ukr.net
}

\begin{abstract}
The main purpose of the publication is to develop theoretical and methodical principles for the creation of local integrated production and trading systems in the region on the basis of main determinants and assessment of the preconditions formation level study results systematization.
\end{abstract}

It is emphasized that there are integration interests in small and medium-sized agricultural producers, business entities in the field of processing industry, retail and wholesale traders in the organization of sales of fresh agricultural products and products for their processing. It is emphasized that the creation of local integrated production and trading systems requires the formation of information, innovation, investment and staffing support, as well as the use of management experience in the field of procurement, processing and sales of such products, which are owned by a system of consumer cooperation.

Identified peculiarities and isolated the problematic aspects of the cooperative enterprises (organizations) functioning in the conditions of competitive environment complication, the presence of multi-sectoral nature of activity and long-term integration links between the entities of cooperative procurement, processing, restaurant, trade. The integration interests of consumer co-operation enterprises (organizations) and the integration objective of participants of the local integrated production and trading system are determined. It is concluded that the further development of cooperative enterprises (organizations) is largely mediated by their ability to participate (initiation of creation) in local integrated production and trading systems and is directly related to the formation of appropriate macro and microeconomic conditions (institutional, organizational and resource) .

It is recommended to use taxonomic analysis tools to assess the level of conditions formation for the creation of local integrated production and trading systems. Taking into account 34 factors of influence with the distribution of stimulants and stimulants allowed to consider the dynamics of the taxonomic index for 2000-2017 years and to confirm the necessity of consumer cooperation enterprises (organizations) participation in integration processes.
The conceptual scheme of development potential management of the local integrated production and trading system is proposed.

Keywords - local integrated production and trading system, determinants of creation, formation of conditions.

\section{INTRODUCTION}

In modern conditions of economic development of Ukraine, which are conditioned by the influence of the financial and economic crisis and political instability, the imperfection and incompleteness of the economy reforms, agricultural commodity producers, especially small and medium ones, faced the problem of ensuring the competitiveness of their products and organizing their sales both on the domestic market and on open foreign markets. The aggravation of this situation is accompanied by saturation of the domestic market with imported agricultural products and foodstuffs of often low quality and, as a result, a reduction in the volumes of domestic agricultural production and an increase in import dependence that threatens the country's food security. In addition, in the period of the transformational changes in the Ukrainian economy, the established economic ties in the technological chain of production, processing and sale of agricultural products were destroyed, and between different organizational and legal forms of management and property by agricultural producers, business entities in the processing industry, and effective sectoral-branch relations have not been created in the area of commodity circulation. It should be noted that there is active development and merging of technologies, which practically blurs the boundaries between physical, digital and biological spheres, and, accordingly, fundamentally changes the principles of production and trading processes and the functioning of traditional business models.

Based on the circumstances in the process of forming a 
multi-pronged agrarian sector of the Ukrainian economy, it is important, firstly, to use the potential of integration and cooperation for the creation of local integrated production and trading systems; and secondly, to propose mechanisms and tools for building the potential for their development and effective functioning. In this case, the synergistic effect will include both economic (mobilization in the circulation of local resources of agricultural raw materials, production of competitive food products, scale effects, savings in transaction costs) and social components (rural development, increase of living standards for rural residents, production of quality and safe products food).

\section{ANALYSIS OF PUBLICATIONS AND THE RESEARCH PURPOSE}

Problems of integration of business entities are devoted to the research of such scholars as A. Cherep [1], Y. Ivanov, [2], A. Pylypenko [2], A. Mazaraki [3], N. Skopenko [4], A. Stergligova [5], M. Voinarenko [6] and others. The theoretical and practical aspects of the creation and development of integrated systems, in particular in the agroindustrial complex, are researched in the works of such domestic and foreign scientists as V. Apopiy [7], L. Berezina [8], O. Borodina [9], T. Bosona [10], G. Gebresenbet [10], G. Cherevko [11], T. Dozorova [12], E. Gusakov [13], V. Gusakov [14], L. Hanushchak-Yefimenko [15], D. Krysanov [16], [17], O. Varchenko [17], E. Kydyrbayeva [18], M. Malik [19], Y. Nesterchuk [20] and others.

At the same time, despite the significant contribution of the scholars to the research on the problems of the creation of integrated systems, the available scientific publication stend to bind integrated systems forming with the creation of agricultural service cooperatives, ignoring historical experience, existing competences, resource potential of the enterprises of the consumer cooperation system in the organization of procurement, processing and marketing of agricultural products.

The main purpose of the publication is to develop theoretical and methodical principles for the creation of local integrated production and trading systems in the region on the basis of main determinants and assessment of the preconditions formation level study results systematization.

\section{RESEARCH RESULTS}

Transformation processes in the agrarian sector of Ukraine led to the destruction of economic relations and the breakdown of technological links in agriculture-production chains, worsening of the safety and quality of agricultural raw materials and end products [17]. Owners of personal peasant and farm enterprises are forced to engage not only in agricultural production, but also seek ways to market their products in conditions of increased competition in the market. At the same time, the problems of finding stable sources of quality agricultural raw materials, innovations and investments, markets for food products fell on the shoulders of entrepreneurs in the processing industry. In this situation, it is urgent to use the potential of integration and cooperation and the creation of local integrated production and trading systems. The model of such a system is presented in [21].

The study of the current situation in the production and further promotion of agricultural products revealed the existence of significant integration interests in potential participants in local production and trade integrated systems - small and medium-sized agricultural producers, business entities in the processing industry, retail and wholesale traders involved in the organization of sales of fresh agricultural products and products of their processing concerning:

- creation and development of a stable raw material base;

- expansion and modernization of production capacities, implementation of progressive energysaving technologies;

- investing in the production of competitive profitable food products, in preserving the quality of fresh and processed agricultural products on the way of its commodity sales;

- improvement of the system of commodity sales, optimization of logistic channels, promotion of the brand;

- expansion of the product offer, prompt introduction of new products into the market, differentiation of the range of products and prices for different categories of consumers;

- reduction of production and sales costs, optimal pricing;

- diversification and expansion of markets, including export;

- ensuring the stability and durability of economic relationships;

- coordination of interaction within the technological chain, innovation processes, management systems, quality control and product safety;

- a combination of science and practice, the formation of intellectual capital, the exchange of knowledge and competences, etc.

Creation of local integrated production and trading systems requires the formation of both in formation, innovation-investment and staffing support, as well as the use of managerial experience in procurement, processing and marketing of agricultural products owned by consumer cooperatives. It is the enterprises of consumer co-operation (procurement, production, trade, transport) can become the initiators of the creation of local integrated production and trading systems.

During the long historical period, the system of consumer co-operation functions as a multi-sectoral complex, connected with the development of rural areas and ensuring welfare of the rural population. Summarizing the historical path of consumer co-operation development, T. Dozorova [12] outlined the following trends: consumer co-operation at various stages corresponded to the level and nature of the development of productive, economic and social relations; she was able to adapt to adverse conditions and changes in the environment; at each stage, potential opportunities for more sustainable development were created; the positive direction of co-operation is particularly evident in the period of socio-political changes and crisis 
phenomena and is related to the solution of food supply issues. In this system considerable experience has been accumulated, competencies have been formed, a material and technical base has been built, and the personnel composition has been prepared in the field of harvesting, processing of agricultural raw materials, sale of processing products and other food and non-food products, their export, and even in the production of agricultural products. Note that precisely harvesting, processing and marketing of agricultural products are those important links in the agroindustrial chain, the leveling of their importance can undermine the overall effect of investing funds directly into agricultural production.

The expediency of involvement in the integration processes of cooperative enterprises (organizations) is due to the following features of the functioning of this economic system:

- proximity to the direct producers of agricultural products,

- accumulated experience of cooperation with them, loyalty of rural inhabitants to the system of consumer co-operation;

- involvement in the circulation of raw materials, labor and financial resources in a certain territory (mainly in rural areas);

- availability in the consumer cooperatives of production capacities of procurement and processing enterprises, an extensive trading network and restaurant facilities;

- professional knowledge and competence in the organization of activities, management experience in a multi-sector economy with integration links;

- availability of intellectual and personnel and research support and sufficient professional training of employees;

- high motivation and control of efficiency of activity, since the owners of the company are members of the cooperative;

- use of the benefits of cooperative labor, savings in production and consumer spending.

At present, the gross turnover of enterprises (organizations) of consumer co-operation of Ukraine is UAH 5440.6 million, including turnover of retail trade network UAH 4309.5 million (79.2\%), and enterprises of restaurant industry - UAH 668.6 million (12.3\%) (Table 1). The development of gross commodity turnover $(\gamma)$ has a positive tendency and is described by the power function:

$$
\gamma=2942 \eta^{0,262}
$$

This allows us to speak about potential opportunities for the development of consumer cooperative activity and expansion of its market niche, including through participation in integration processes.

We investigated the density of integration relationships between different branches of the cooperative economy of Ukraine during 2000-2017 with the aid of a correlation analysis tool. It has been revealed that the deepest are the integration links between the branches of trade and restaurant industry $(\mathrm{R}=0.813)$, harvesting and industrial processing $(R=0.826)$, harvesting and catering $(R=0.817)$. The integration links between the restaurant industry and the industrial processing industry $(\mathrm{R}=0.403)$, between retail trade and manufacturing $(\mathrm{R}=0.490)$ and procurement sectors $(\mathrm{R}=0.597)$ are identified as moderate. Revealed tendency of weakening of integration links between the main branches of the cooperative economy emphasizes the importance of finding new forms of internal and external integration of enterprises (organizations) of consumer cooperation.

TABLE I. INDICATORS OF ECONOMIC AND FINANCIAL ACTIVITY OF ENTERPRISES OF THE CONSUMER CO-OPERATION OF UKRAINE IN 2000-2017 [22]

\begin{tabular}{|c|c|c|c|c|}
\hline \multirow{2}{*}{ Year } & \multicolumn{4}{|c|}{ Indicators } \\
\cline { 2 - 5 } & $\begin{array}{c}\text { Gross } \\
\text { turnover, } \\
\text { mIn. UAH }\end{array}$ & $\begin{array}{c}\text { Chain rates of } \\
\text { change in gross } \\
\text { turnover, \% }\end{array}$ & $\begin{array}{c}\text { The share of profitable } \\
\text { enterprises, \% to total }\end{array}$ & $\begin{array}{c}\text { Profit, } \\
\text { mln. } \\
\text { UAH }\end{array}$ \\
\hline 2000 & 2416.5 & 101.7 & 62.7 & -62.1 \\
\hline 2005 & 3627.3 & 118.2 & 90.1 & 34.5 \\
\hline 2006 & 3977.2 & 109.6 & 92.7 & 56.4 \\
\hline 2007 & 4463.6 & 112.2 & 94.9 & 113.7 \\
\hline 2008 & 5222.9 & 117.0 & 97.0 & 146.0 \\
\hline 2009 & 5268.7 & 100.9 & 97.3 & 101.9 \\
\hline 2010 & 5624.8 & 106.8 & 99.2 & 85.0 \\
\hline 2011 & 6188.5 & 110.0 & 98.9 & 105.6 \\
\hline 2012 & 5866.5 & 94.8 & 98.5 & 125.0 \\
\hline 2013 & 5545.6 & 94.5 & 98.2 & 164.4 \\
\hline 2014 & 4997.3 & 90.1 & 97.4 & 120.9 \\
\hline 2015 & 4652.9 & 93.1 & 98.3 & 158.9 \\
\hline 2016 & 5039.9 & 108.3 & 98.4 & 182.7 \\
\hline 2017 & 5440.6 & 108.0 & & 98.5 \\
\hline
\end{tabular}

Integration in this case is considered as an association of enterprises of consumer co-operation with other subjects of the agro-industrial complex on the basis of processes of specialization and concentration and the creation of a holistic economic mechanism by coordinating economic interests, coordinating business processes and relationships, optimizing the size and joint effective use resource potential, exchange of competences and knowledge to achieve a single integration goal [21].At the same time, the integration interests of cooperative enterprises participating in the local integrated production and trading system are: modernization and expanded reproduction of resource potential on an innovative basis; development of production and trading activity and ensuring its high efficiency; improvement of competitive positions in the domestic market at the expense of production and sales of highquality food products (targeting import substitution), access to the foreign market with competitive products under its own brand (export orientation), expansion of the market niche; optimization of business processes, expenses and strengthening of economic safety; implementation of the social function of consumer cooperatives in rural areas. 
The further development of cooperative enterprises (organizations), strengthening of their competitiveness and viability are largely mediated by their ability to participate (initiation of creation) in local integrated production and trading systems and is directly related to the formation of appropriate macro- and microeconomic conditions (institutional, organizational and resource) (Fig. 1).

They are presented by the conditions of institutionalization of integration cooperation, the state and level of resource potential of potential participants of the integrated system and innovation and investment support of its activities, availability to the raw material base, markets, knowledge and motivational aspects.

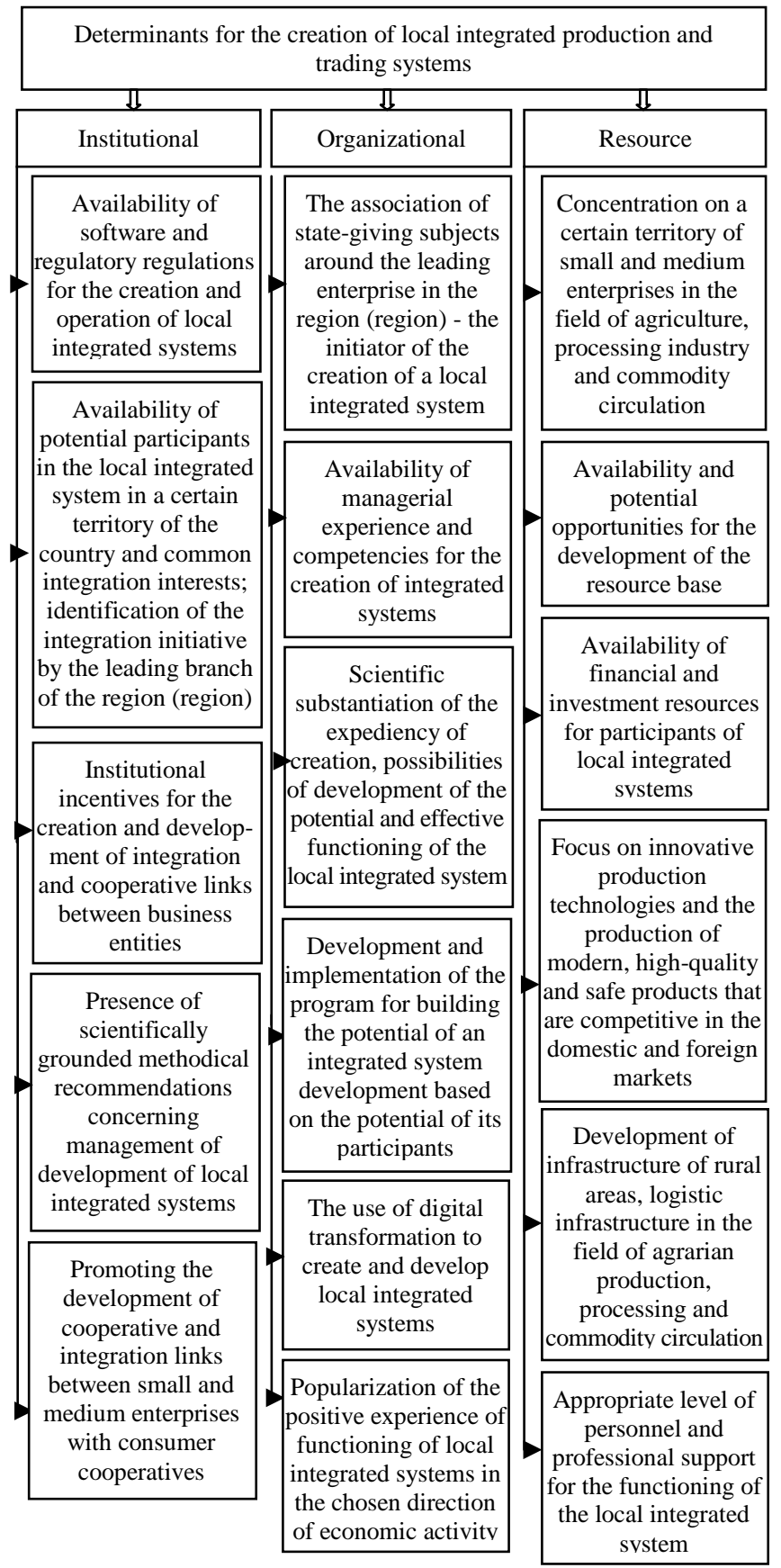

Fig. 1. Determinants for the creation of local integrated production and trading systems
A significant obstacle to the creation of integrated local production and trading systems is the imperfection of the normative and regulatory framework for stimulating the production and marketing of agrarian products, easing the state support for agricultural producers and processing enterprises, manifestations of raids and corruption.

The use of taxonomic analysis tools was proposed to assess the level of formation of conditions for the creation of local integrated production and trading systems. The advantage of this method of research is the ability to take into account heterogeneous and operating factors in different directions.

In the course of the research according to the official statistics and departmental materials of the Ukrainian consumer co-operation, a matrix of 34 indicators was formed. To standardize the values of the elements of the output matrix, the average value for each indicator is used. In order to construct the reference vector, indicators were divided into stimulants and decelerators.

Among stimulants we considered such as: export volume of agricultural and food products; retail turnover of food products per capita per year; the level of employment in rural areas; the share of population farms and farms in the production of agricultural products; share of members of consumer societies in rural population, etc.

Decelerators were: the level of inflation; share of readymade foodstuffs in the volume of imports; the level of depreciation on fixed assets of consumer cooperation; share of loss-making enterprises of consumer cooperation, etc. The determination of the taxonomic indicator was based on the calculation of the distance between the individual observations and the vector reference.

The use of a significant dynamic range of baseline indicators (2000-2017 years) revealed the taxonomic index change over this period and presented it graphically on Fig. 2.

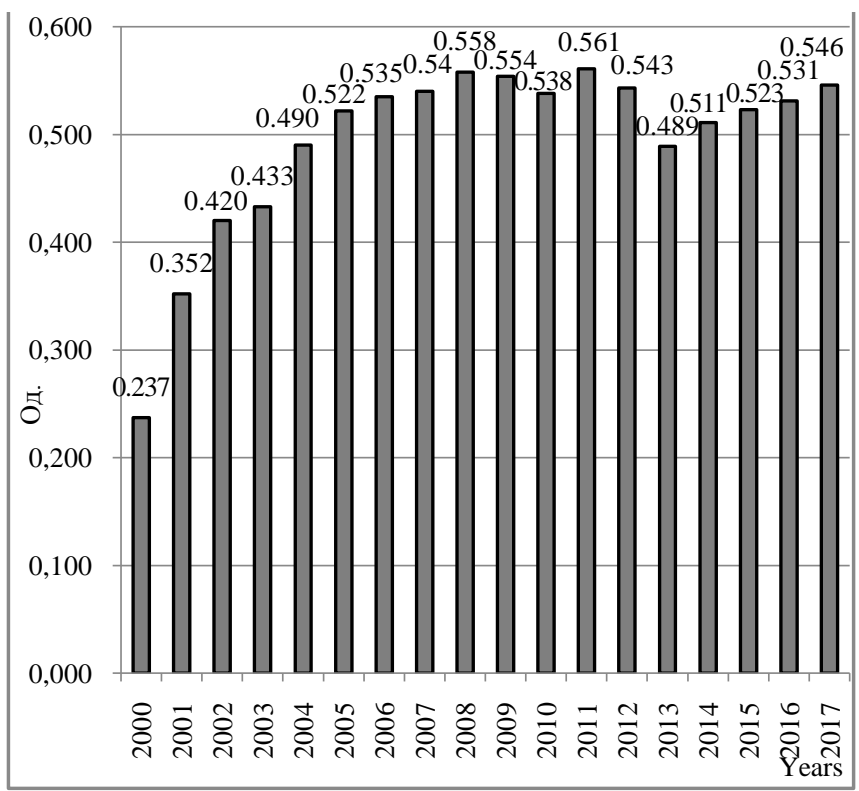

Fig. 2. Taxonomic index of the level of the formation of conditions for the creation of local integrated production and trading systems in 2000-2017

The most favorable for the creation of local integrated production and trading systems with the participation of 
consumer cooperatives were 2008, 2009 and 2011. In recent years, there has been a tendency to improve the conditions for the establishment of such systems, which confirms the need for participation of enterprises (organizations) of consumer co-operation in integration processes.

The conceptual scheme of local integrated production and trading system potential development management is presented in Fig. 3.

At the same time, given the long-term nature of the expected integration links of the participants, a special place is devoted to the formation of a strategy for its development and effective functioning. We will emphasize the need to identify the main sources of funding for building the potential of the integrated system development, and for its further effective functioning, as well as motivational and organizational and economic tools.

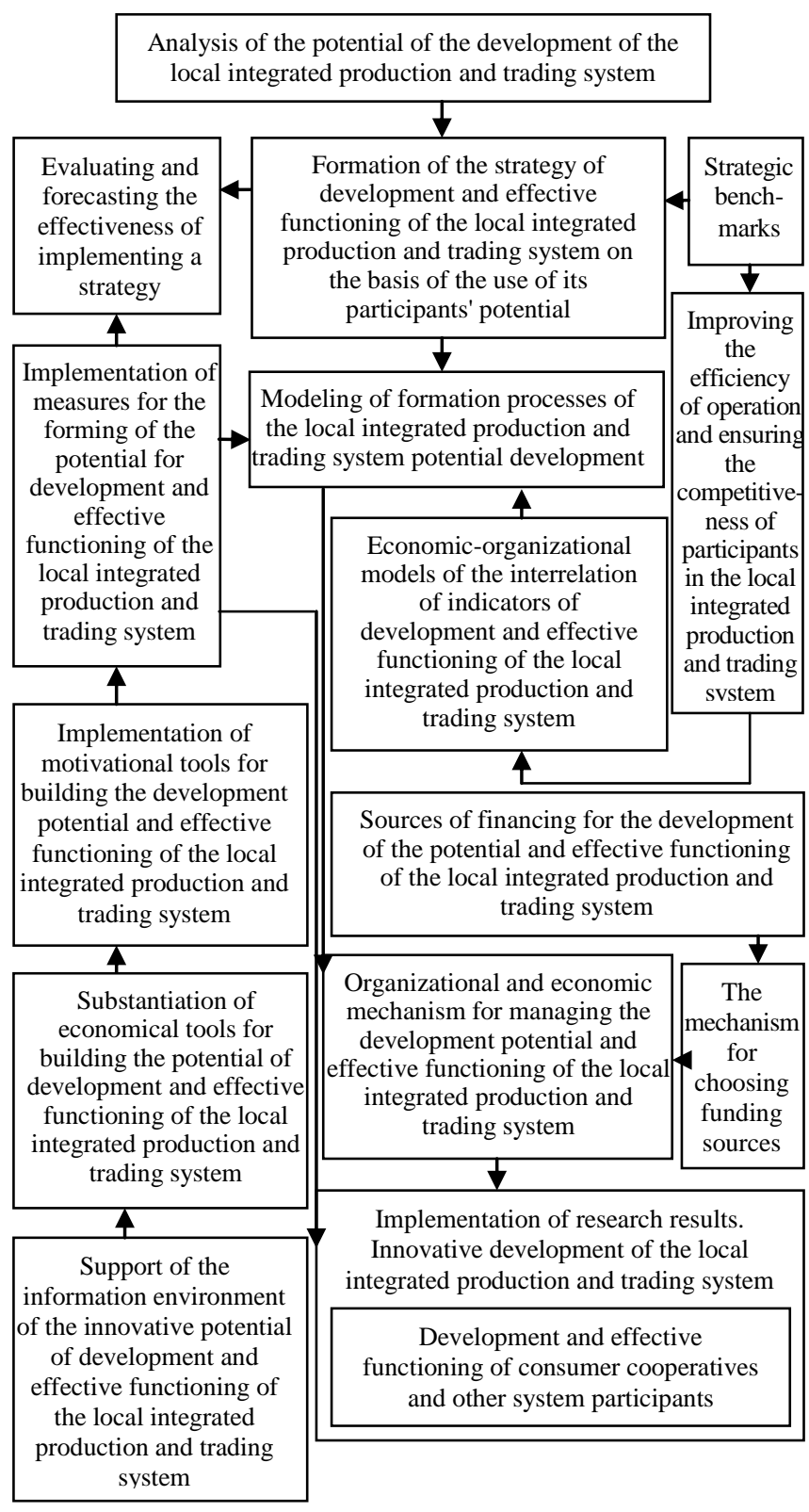

Fig. 3. The conceptual scheme of management of the local integrated production and trading system potential development.
We emphasize that for local integrated production and trading systems, the main technological trends in the formation of an information environment in the field of digital transformation are: the introduction of industrial Internet of things and robotic technologies; transition to "cloud" technologies of information storage and conducting of calculations, transition to electronic document circulation; through automation and integration of production, trade and information processes into a single information system; application of technologies big data; digital design and simulation of technological operations and objects; application of services of automatic ordering of resources for production of products and supplies of goods to consumers, bypassing intermediary structures; use of unmanned technologies in the process of transportation of raw materials and finished products; application of mobile technologies for monitoring, control and management of basic technological processes; transition to the sale of goods and services through the Internet.

The above will allow to provide innovative orientation of activity of the local integrated system, competitor's competence and economic safety of its participants.

\section{CONCLUSIONS}

In the research further development was gained by theoretical and methodological principles for the creation of local integrated production and trading systems, in particular, the involvement of enterprises (organizations) of consumer co-operation in integration processes was substantiated, with further formation of conclusions regarding the consequences of the development of the functioning of such systems.

It is established that the necessary prerequisite for the development of integrated production and trading systems in the agrarian sector with the participation of consumer cooperation should be the presence of significant integration interests of potential participants in the local industrial and trading integrated systems - subjects of agroindustrial complex, and compatible with them integrative interests of trade co-operation enterprises on modernization and expanded reproduction of resource potential, development of production and trading activities, improvement of their competitive positions in the internal market, optimization of business processes, realization of social function of consumer cooperation in rural territories, etc. - on the basis of processes of specialization and concentration and creation of integral economic mechanism through coordination of economic interests, coordination of business processes and relations, optimization of sizes and joint efficient use of resource potential, exchange of competences and knowledge to achieve a unified integration goal.

Success in solving problems related to creation of local integrated production and trading systems can be ensured only under conditions of formation of appropriate macroand microeconomic conditions, including information, innovation-investment, human resources and related use of managerial experience, definition of adapted to the level of conditions formation for creation of local integrated production and trading systems strategy of their development and effective functioning, availability of reliable sources of financing for capacity building of integrated systems, development of motivational and 
ekonomic-organizational tools as well as the conditions to overcome the problems of imperfections of regulatoryadministrative and institutional framework for stimulating production and marketing of agricultural products, manifestations of raiding and corruption, strengthening state support of agricultural producers and processing enterprises.

Creation of effectively functioning local integrated production and trading systems and the participation of enterprises (organizations) of consumer co-operation in internal and external integration processes will allow to influence the state of the domestic consumer market, first of all, in rural areas, to provide food and economic security of the country.

The economic consequences of the formation of these local integrated systems are the development and innovation orientation of the activities of both the systems themselves and cooperative participating enterprises; involvement in the circulation of raw material resources of agricultural products of personal peasant and farm enterprises; establishment of production and saturation of the market with quality food products; creation of an effective system of commodity sales of fresh and processed agricultural products through channels of cooperative wholesale and retail trade, harvesting and catering; the formation of competitive food supply for the European market.

Social effects are: increased purchasing funds and solvent demand of the rural population; improving living standards in rural areas; improvement of ecological conditions on the territory of activity; development of rural territories.

It has been established that in recent years the integration links between the sectors of the cooperative economy have weakened, while the conditions for the participation of cooperative enterprises (organizations) in integration processes are improving (the level of formation of conditions for this is 0.546 ).

To create local integrated production and trading systems, it is necessary to create the appropriate preconditions: institutional, organizational and resource.

The conceptual scheme of local integrated production and trading system potential development management, the implementation of which will allow to provide an innovative orientation of the system's activity, competitiveness and economic safety of its participants, is proposed.

Prospects for further scientific developments relate to the development of mechanisms and tools for integration cooperation of participants in integrated systems, consolidation of their economic interests.

\section{REFERENCES}

[1] A. V. Cherep, H. D. Pohota, and K. S. Brutian, Activities of enterprises of industrial and financial groups of the food industry in market conditions of management. Kyiv: Kondor, 2009.

[2] Yu. B. Ivanov, and A. A. Pylypenko, Integrative development of business entities: theoretical substantiation and organization of management. Kharkiv: VD "Inzhek”, 2012.
[3] A. A. Mazaraki, and M. V. Bosovskaya, "Theoretical and methodological principles of formation of enterprise integration strategy", Business Inform, vol. 7, , pp. 299-308, 2013.

[4] N. S. Skopenko, "Theoretical justification for the integration of economic entities", Theoretical and applied issues of economics, vol. 26, pp. 187-195, 2011.

[5] A. N. Sterligova, Theoretical and methodological foundations of the level integration of the company in a network competition. Moscow: Publishing house of the Moscow State Educational University, 2008.

[6] M. P. Voinarenko, Clowns in the institutional economy. Khmelnitsky: TOV "Triada-M", 2011.

[7] V. V. Apopij, Internal trade and agroindustrial complex of Ukraine: effectiveness of interaction. Lviv: LKA, 2007.

[8] L. M. Berezina, "Integration processes of agricultural enterprises: organizational and economic aspects", Economics of today: current issues and prospects, vol. 2, pp. 175-182, 2013.

[9] O. M. Borodina, "Integration of small agricultural producers into the agro-foodchains of added value: methodological approaches and empirical studies", Economy and Forecasting, vol. 2, pp. 73-84, 2014

[10] T. G. Bosona, and G. Gebresenbet, "Cluster building and logistics network integration of local food supply", Chain original research article, Biosystems Engineering, vol. 108(4), pp. 293-302, 2011.

[11] G. V. Cherevko, "Integration processes in agroindustrial complex: prospects for attracting consumer cooperatives to them", Bulletin of Lviv Commercial Academy, vol. 47, pp. 24-29, 2015.

[12] T. A. Dozorova, "A retrospective analysis of the evolution of development of the domestic theory and practice of agricultural consumer cooperation", International agricultural journal, vol. 1 (367), pp. 12-16, 2019.

[13] E. V. Gusakov, Scientific bases and organizational and economic mechanism of effective functioning of cooperative and integration associations in agriculture. Minsk: Publishing house "Belarusianscience", 2015.

[14] V. G. Gusakov, and M. I. Zapol'skij, Cooperative integration relations in the agrarian sector of the economy. Minsk: Publishing house "Belarusian science", 2010.

[15] L. M. Hanushchak-Yefimenko, "Economic integration as the basis for the development of small and medium-sized businesses", Actual problems of the economics, vol. 3 (141), pp. 70-77, 2013.

[16] D. F. Krysanov, Integration of agro-foodsector of Ukraine into the single regulatory environment of the European Union. Kyiv, 2016.

[17] O. M. Varchenko, D. F. Krysanov, and O. A. Shust, "Innovations of agro-food chains in Ukraine", Agricultural science and practice, vol. 4 (3), pp. 73-83, 2017.

[18] E. O. Kydyrbayeva, B. K. Shomshekova, S. S. Bisenova, and B. H. Kylyshbayeva, "Development of Cluster Integration in Agricultural Sector of the Republic of Kazakhstan", International Journal of Economics and Financial Issues, vol. 6, Special Issue (S5), pp. 65-71, 2016.

[19] M. J. Malik, "Problems of development of cooperation and integration relations in agroindustrial complex", Economics of agroindustrial complex, vol. 3, pp. 3-8, 2010.

[20] Yu. Nesterchuk, and I. Novytskyi, "Interbranch and inter-farm interactions of subjects of agrarian-industrial production", Zeszyty Naukowe PWSZ w Plocku, Nauki Ekonomiczne, vol. 26, pp. 119-131, 2017.

[21] N. H. Mitsenko, "Formation of integrated economic systems in the field of commodity circulation", Trade, commerce, entrepreneurship, vol. 19, pp. 133-141, 2015.

[22] Indicators of economic and financial activity of enterprises and organizations of unions of consumer cooperatives of Crimea, regions for 2017, Kyiv, 2018. 